\title{
Price conversion index
}

\begin{tabular}{lccccc}
\hline Year & Index & Year & Index & Year & Index \\
\hline 1918 & 100.0 & 1926 & 92.3 & 1934 & 79.1 \\
1919 & 109.6 & 1927 & 90.3 & 1935 & 79.6 \\
1920 & 126.5 & 1928 & 90.3 & 1936 & 80.6 \\
1921 & 115.8 & 1929 & 89.3 & 1937 & 83.2 \\
1922 & 99.5 & 1930 & 86.7 & 1938 & 84.2 \\
1923 & 93.9 & 1931 & 83.2 & 1939 & 87.2 \\
1924 & 92.9 & 1932 & 81.1 & & \\
1925 & 93.4 & 1933 & 79.1 & 2001 & 3206.1 \\
\hline
\end{tabular}

This index is provided to help readers convert spending between the wars to modern equivalents. To ascertain this for any year compared to (say) 2001, the index for 2001 (i.e. 3206.1) should be divided by the index for the year in question. So to find out how much $£ 1$ in 1920 was worth in the year 2001 you would divide 3206.1 (the index for 2001) by 126.5 (the index for 1920), giving the answer $£ 25.34$. (All long-term price indices should be treated with caution because the nature of goods purchased has changed over time.) 
Mike Huggins - 9781526120632 Downloaded from manchesterhive.com at $04 / 26 / 2023$ 12:23:18PM via free access 